\title{
Vegetative and gametic flagellum membranes of Chlamydomonas reinhardtii
}

\author{
ALEKSANDER F. SIKORSKI \\ Institute of Biochemistry, University of Wrocław, \\ ul. Tamka 2, 50-137 Wrocław, Poland
}

(Received: May 30, 1979)

\begin{abstract}
Differences were demonstrated in the composition, electrophoretic patterns of polypeptide chains and neutral sugar composition between vegetative and gametic flagellum membranes of two strains (89 and 90) of Chlamydomonas reinhardtii.
\end{abstract}

\section{INTRODUCTION}

Under conditions of nitrogen starvation opposite mating type vegetative cells of Chlamydomonas reinhardtii undergo gametogenic differentiation to produce 'gametes' which fuse to form a zygote.

As a consequence of this process the gametic flagella become characteristically adhesive. This adhesiveness is lost when the gametes fuse to form a zygote, or upon addition of ammonia or nitrate to the culture medium ( $\mathrm{K}$ a t e s and J o n e s, 1964). W i e s e (1971) noted that whereas proteases such as trypsin, subtilisin and pronase destroyed the adhesive quality of gametic flagella, glycosidases such as mannosidase, galactosidase and neuraminidase had no effect. No apparent differences in the surface ultrastructure of gametic (adhesive) or vegetative (non-adhesive) flagella were observed. However Berg man et al. (1975) and Snell (1976) using freeze-cleave techniques suggested that there might be differences in the density of intramembranous particles.

In the present paper some properties of gametic and vegetative flagellum membranes are compared.

\section{MATERIAL AND METHODS}

Chlamydomonas reinhardtii strains 89 and 90 received from $\mathrm{dr}$ R. F. Jones of Cellular and Comparative Biol. Dept., State Univ. of New 
York, Stony Brook were used. Cultures and gamete induction were carried out according to $\mathrm{K}$ a tes and $\mathrm{J}$ o n e s (1964).

Neutral sugars anaiyses by gas-liquid chromatography of alditoi acetate derivatives were performed according to $\mathrm{Sefton}$ and $\mathrm{K}$ e e g stra (1974) and Ke egstra et al. (1975). Washed five times with water freshly prepared membranes were lyophilized and subjected to hydrolysis, reduction and acetylation. Myoinositol (10 $\mu \mathrm{g}$ per sample) was added as an internal standard. Chromatography was performed on a Hewlett-Packard Gas Chromatograph 5710 with flame ionization detector and electronic (H-P. 3370B) integrator. Alditol acetates were separated on a $182.9 \mathrm{~cm}$ glass column packed with $1 \%$ OV-275 on Gas Chrom Q. Samples were injected at column temperature $140^{\circ} \mathrm{C}$. After $4 \mathrm{~min}$. the temperature was raised at a rate of $1^{\circ} \mathrm{C} / \mathrm{min}$. to the final temperature of $210^{\circ} \mathrm{C}$ and was maintained for $8 \mathrm{~min}$.

Calibration curves of the logarithm of molecular weight and migration distance in 5.6 and $7.5 \%$ polyacrylamide gel electrophoresis in the presence of $0.1 \%$ SDS relations were obtained for some standard proteins: $\gamma$-globulin, bovine serum albumin, ovoalbumin, chymotrypsinogen and cytochrome c. Data for $\gamma$-globulin were obtained by electrophoresis in nonreducing conditions.

Chemicals: bovine serum albumin, $\gamma$-globulin (Plasma fraction II), chymotrypsinogen were purchased from Sigma. Cytochrome c from Mann and standard monosaccharides from Calbiochem. OV-275 and Gas Chrom Q were obtained from Applied Sci. Labs.

The other materials and methods have already been described (S i k or ski, 1979).

\section{RESULTS AND DISCUSSION}

Gametic flagellar membranes of strains (89 and 90) display decreased relative protein and increased carbohydrate and phosphorus contents when compared with the vegetative ones (Table 1).

\section{Table 1}

Protein, carbohydrate and phospholipid contents in Chlamydomonas flagellum membranes vegetative and gametic of strains 89 and 90. Data obtained for pelleted membranes. Protein was determined according to Hartree (1972), sugars by the Dubois et al. (1956) procedure and phosphorus according to Bartlétt (1958). In this analysis two assumptions were made - components determined here represent total dry weight and phospholipid content $=$ phosphorus content $\times 25$

\begin{tabular}{|l|c|c|c|}
\hline \multicolumn{1}{|c|}{ Strain } & $\begin{array}{c}\text { Protein } \\
\%\end{array}$ & $\begin{array}{c}\text { Carbohydrate } \\
\%\end{array}$ & $\begin{array}{c}\text { Phospholipid } \\
\%\end{array}$ \\
\hline 89 vegetative & 54.1 & 33.82 & 12.07 \\
89 gametic & 48.91 & 34.96 & 16.13 \\
90 vegetative & 49.94 & 34.96 & 15.10 \\
90 gametic & 45.13 & 37.95 & 16.92 \\
\hline
\end{tabular}


Figs 1,2 and 3 present electrophorograms of membrane proteins of 89 and 90 vegetative and gametic flagellum membranes stained with Coomassie blue and Shiff reagent.

Although the number of protein bands is the same in both strain 89 membrane types, a substantial decrease of fraction '4' and increase of fraction ' 5 ' in Coomassie blue staining is observed in gametic membranes (Figs 1 and 2). The differences in polypeptide fractions between the two membrane types of strain 90 (Fig. 3) also concern fractions of intermediate molecular weight, namely, complete decay of fraction ' 3 ' and apperance of band ' $3 \mathrm{a}$ ' is observed. In both strains no differences in PAS-possitive components distribution between gametic and vegetative flagellar membranes were observed.

It should be noted that the differences in glycoprotein distribution between strains 89 and 90 (both vegetative and gametic) flagellar membranes were observed. High molecular weight glycoprotein (fraction '1') of strain 90 membranes was divided into two bands observed also in Coomassie blue staining. In the case of strain 90 gametic flagellum membranes bands '4', '5' and '6' are stained with Coomassie blue very weakly and their mobilities were judged from radioactive tracing of the gels in which ${ }^{125}$ I labeled membranes were run.

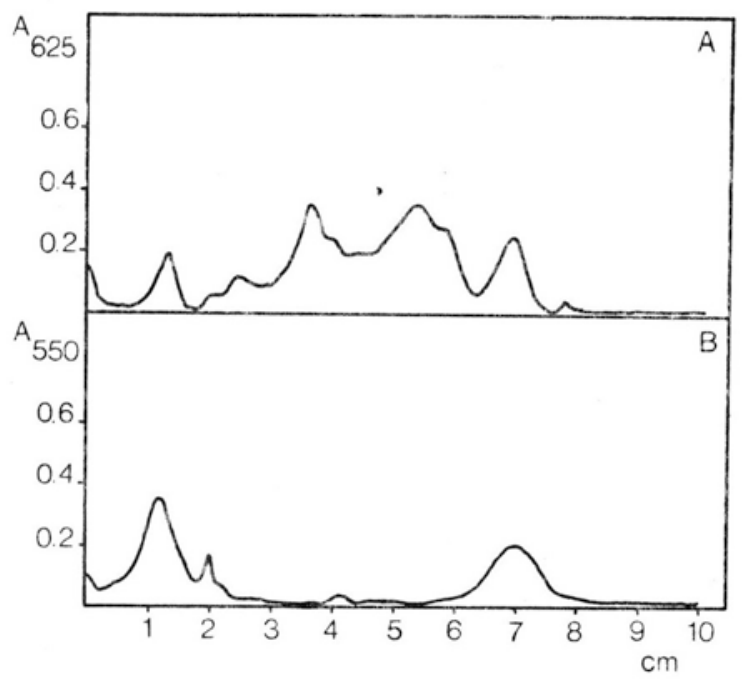

Fig. 1. SDS-polyacrylamide gel electrophoresis of strain 89 vegetative flagellum membranes. $5.6^{\circ} \%$ gel, $0.1 \%$ SDS.

a - Coomassie blue staining $-100 \mu \mathrm{g}$ of protein; b - PAS-positive components $-50 \mu \mathrm{g}$ of protein.

In Table 2 relative molecular weight values of individual membrane polypeptide chains are shown. Some of those data were obtained for isolated individual fractions run also in $7.5 \%$ gel. Aldose content in 


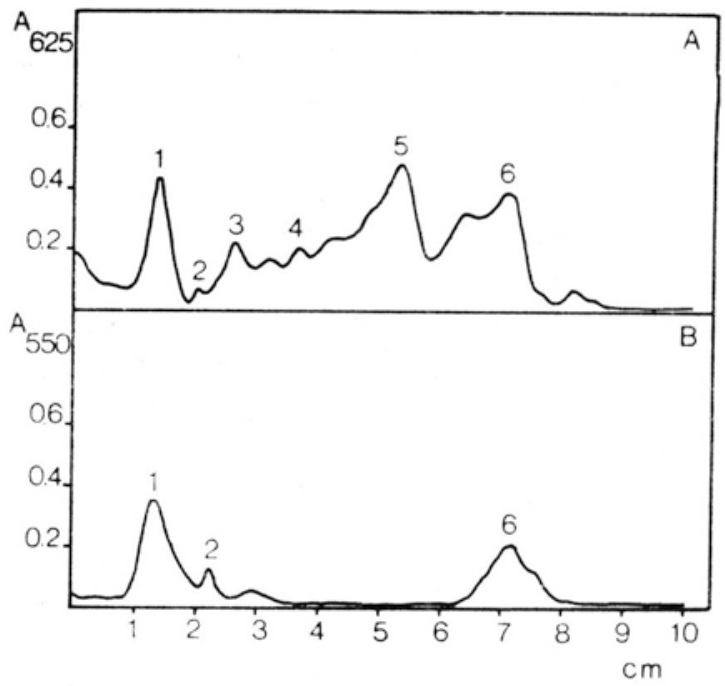

Fig. 2. SDS-polyacrylamide gel electrophoresis of strain 89 gametic flagellum membranes. $5.6 \%$ gel. $0.1 \%$ SDS.

a - Coomassie blue staining $-100 \mu \mathrm{g}$ of protein; b - PAS-positive components $-50 \mu \mathrm{g}$ of protein.

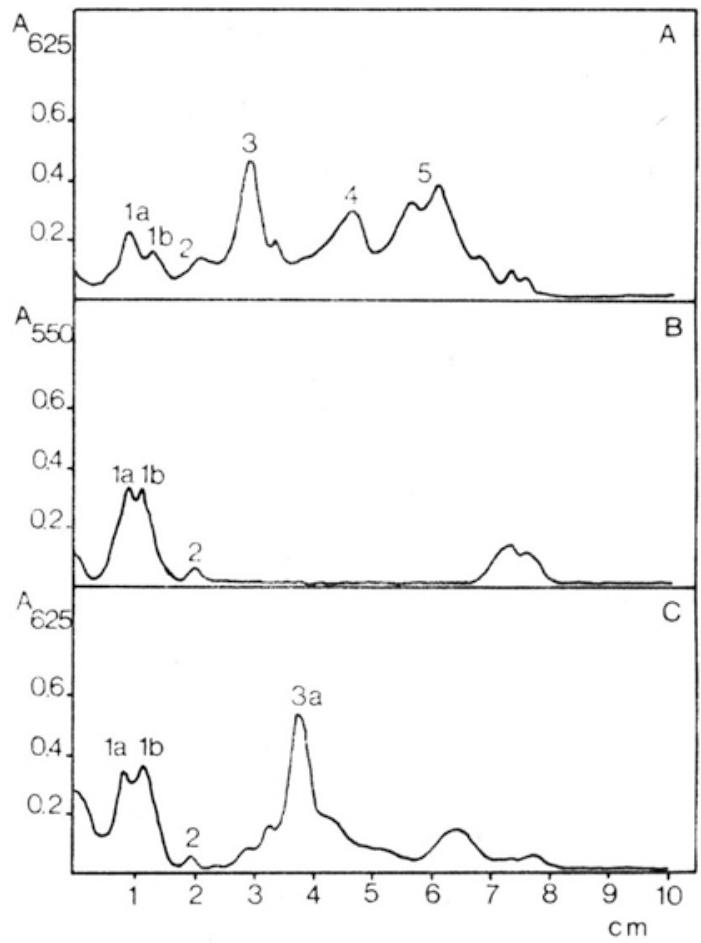

Fig. 3. SDS-polyacrylamide gel electrophoresis of strain 90 flagellum membranes. $5.6 \%$ gel, $0.1 \%$ SDS.

a - vegetative membranes, Coomassie blue staining - $100 \mu \mathrm{g}$ of protein; b - vegetative membranes, PAS-positive components - $50 \mu \mathrm{g}$ of protein; c - gametic membranes, Coomassie blue staining $-100 \mu \mathrm{g}$ of protein. 
all four types of analysed membranes represents $60-65 \%$ of total membrane sugar determined by phenol reagent. In all the analysed membrane preparations the following hexoses were found: glucose, galactose, mannose and rhamnose (Table 3). The relative glucose content of strains 89 and 90 vegetative flagellum membranes is 43.7 and $43.2 \%$, respectively, whereas for gametic ones 58.1 and $49.1 \%$. Mannose content shows an inverse relation - for strain 89 vegetative flagellum membranes $33.95 \%$ and for gametic ones $24.6 \%$, and for strain $90-36.99$ and $25.45 \%$ respectively. Galactose and rhamnose contents show no evident regularity. It should be noted that no qualitative differences in aldose composition were found.

\section{Table 2}

Relative molecular weight values of individual polypeptide fractions determined on the basis of their mobility in 5.6 polyacrylamide gel in the presence of $0.1 \%$ SDS

\begin{tabular}{|c|c|c|c|c|c|}
\hline \multicolumn{3}{|l|}{ Strain 89} & \multicolumn{3}{|c|}{ Strain 90} \\
\hline \multirow{2}{*}{$\begin{array}{c}\text { Fraction } \\
\text { no. }\end{array}$} & \multicolumn{2}{|c|}{ Molecular weight $\times 10^{5}$} & \multirow{2}{*}{$\begin{array}{c}\text { Fraction } \\
\text { no. }\end{array}$} & \multicolumn{2}{|c|}{ Molecular weight $\times 10^{5}$} \\
\hline & Vegetative & Gametes & & Vegetative & Gametes \\
\hline 1 & 1.73 & 1.73 & $1 \mathrm{a}$ & 2.0 & 2.0 \\
\hline 2 & 1.258 & 1.202 & $1 b$ & 1.73 & 1.73 \\
\hline 3 & 0.977 & $0.9770 .777^{*}$ & 2 & 1.38 & 1.38 \\
\hline 4 & 0.602 & $0.6020 .575^{*}$ & 3 & 0.832 & - \\
\hline 5 & 0.302 & $0.3020 .372: 0.28^{*}$ & $3 \mathrm{a}$ & - & 0.562 \\
\hline 6 & 0.151 & 0.151 & 4 & 0.416 & 0.363 \\
\hline \multirow[t]{2}{*}{ Tubulin } & \multirow[t]{2}{*}{0.537} & \multirow[t]{2}{*}{$0.560^{*}, 0.537^{*}$} & 5 & 0.229 & 0.229 \\
\hline & & & 6 & 0.141 & 0.141 \\
\hline
\end{tabular}

* - data for some isolated fractions obtained from $7.5 \%$ gel electrophoresis.

Table 3

Neutral sugars content in flagellum membranes of vegetative and gametic cells of strains 89 and $90 \mathrm{Ch}$. reinhardtii, analysed by gas-liquid chromatography of alditol acetates. Details in Material and methods. Average of analyses of two preparations

\begin{tabular}{|l|c|c|c|c|}
\hline \multicolumn{1}{|c|}{ Strain } & $\begin{array}{c}\text { Glucose } \\
\%\end{array}$ & $\begin{array}{c}\text { Galactose } \\
\%\end{array}$ & $\begin{array}{c}\text { Mannose } \\
\%\end{array}$ & $\begin{array}{c}\text { Rhamnose } \\
\%\end{array}$ \\
\hline 89 vegetative & 43.73 & 17.89 & 33.95 & 4.43 \\
89 gametic & 58.14 & 15.70 & 24.61 & 1.55 \\
90 vegetative & 43.22 & 14.85 & 36.99 & 4.94 \\
90 gametic & 49.07 & 18.91 & 25.45 & 6.57 \\
\hline
\end{tabular}

The data presented here connected with other studies particularly of S nell (1976) and B e r g man et al. (1975) supplement the picture of events occurring in the membrane during gametogenesis. 
Electrophoretic determination of molecular weight is of rather relative value, particularly in the case of glycoproteins ( $\mathrm{J}$ a vaid and W in z le r 1974), but it is very useful in comparative studies.

The changes observed in electrophoretic patterns of flagellum membrane polypeptides seem to be in good agreement with the data of Snell (1976), who observed an additional band migrating in the same region in the case of (plus) 'gamone' electrophoretic analysis.

It should be noted that the results presented here concerned membranes isolated from flagella and were connected with both mating types.

In this study it was shown that Chlamydomonas flagellum membranes contain glucose, galactose, mannose and rhamnose. Comparative analysis of neutral sugar content demonstrated considerable differences in their quantities between gametic and vegetative flagella membranes

One could suppose that changes in sugar composition concerned specific synthesis and/or modification of glycoprotein or glycolipid surface receptors of the flagellum membrane. On the other hand, it is possible that the changes observed in the electrophoretic patterns were the consequence of specific glycosyl transferase or glycosidase appearance if the hypothesis of $\mathrm{R}$ os e m a n (1970) or specific lectin if the suggestion of A Shwell and Morell (1977) are accepted.

In the previous report (Sikorski, 1979) the data suggesting loca. tion of fraction ' 5 ' on the external surface of the flagellum membrane of vegetative cells of Chlamydomonas reinhardtii strain 89 were presented. An increased amount of this fraction found during gametogenesis would suggest its receptor function and participation in the mating process.

\section{Acknowledgments}

The author wishes to thank dr R. F. Jones for help and guidance during his stay at Stony Brook.

The author wishes to express his appreciation to drs K. Keegstra and D. Burke for acquainting him with sugars analyses by gas-liquid chromatography.

The advice and valuable discussions during manuscript preparation of Professor W. Mejbaum-Katzenellenbogen of the Institute of Biochemistry, University of Wroclaw are greatly appreciated.

This work was supported in part by INT Grant No. 76/22205.

\section{REFERENCES}

Ashwel1 G., Morel1 A. G., 1977. Membrane glycoproteins and recognition phenomena, TIBS 2: 76-78.

Bartlett G. B., 1958. Phosphorus assay in column chromatography, J. Biol. Chem. 234: 466-468. 
Bergman K., Goodenough U. W., Goodenough D. A., J a witz J., $\mathrm{M}$ a $\mathrm{rtin}$ H., 1975. Gametic differentiation in Chlamydomonas reinhardtii. II. Flagellar membranes and the agglutination, J. Cell Biol. 67: 606-622.

Dubois M., Gilles K. A., Hamilton J. K., Rebers P. A., Smith F., 1956. Colorimetric method for determination of sugars and related substances. Anal. Chem. 28: 350-356.

Hartree E. F., 1972. Determination of protein: a modification of the Lowry method, that gives a linear photometric response. Anal. Biochem. 48: 422-427.

J a vaid J. I., Winzler R. J., 1974. Association of glycoproteins with the membranes. I. Isolaiion and molecular weight of the monomeric unit of the major glycoprotein from human erythrocytes. Biochemistry 13: 3635-3638.

Kates J. R., Jones R. F., 1964. The control of gametic differentiation in liquid cultures of Chlamydomonas reinhardtii. J. Cell Comp. Physiol. 63: 157-164.

Keegstra K., Sefton B., Burke D., 1975. Sindbis virus glycoproteins: Effect of the host cell on the oligosaccharides, J. Virol. 16: 613-620.

R oseman S., 1970. Synthesis of complex carbohydrates by multiglycosyltransferase systems and their potential function in intracellular adhesion. Chern. Phys. Lipids 5: 270-237.

Sefton B. M., Keegstra K., 1974. Glycoproteins of Sindbis virus: preliminary characterisation of the oligosaccharides. J. Virol. 14: 522-530.

Sikorski A. F., 1979. Electrophoretic analysis, labeling and isolation of Chlamydomonas reinhardtii flagellum membrane proteins. Acta Soc. Bot. Pol. 48: 511-521.

Snel1 W. J., 1976. Mating in Chlamydomonas: A system for the study of specific cell adhesion. I. Ultrastructural and electrophoretic analysis of flagellar surface components involved in adhesion. J. Cell Eiol. 68: 48-69.

W iese L., 1971. Nature of sex specific agglutination in Chlamydomonas. Ann. N. Y. Acad. Sci. 243: 383-394.

\title{
Błony wici komórek wegetatywnych i gamet $u$ Chlamydomonas reinhardtii
}

\author{
Streszczenie
}

Wykazano różnice w skladzie, obrazach elektroforetycznych bialek oraz zawartości cukrów obojętnych pomiędzy błonami wici komórek wegetatywnych i gamet dwu szczepów (89 i 90) Chlamydomonas reinhardtii. 